\title{
Comparative study of human exposure to mercury in riverside communities in the Amazon region
}

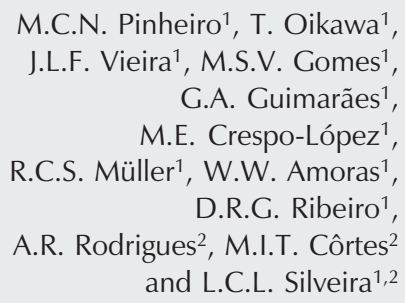

${ }^{1}$ Núcleo de Medicina Tropical and ${ }^{2}$ Departamento de Fisiologia, Universidade Federal do Pará, Belém, PA, Brasil

\section{Correspondence}

M.C.N. Pinheiro

Núcleo de Medicina Tropical

Universidade Federal do Pará

Av. Generalíssimo Deodoro, 82

66055-240 Belém, PA

Brasil

Fax: +55-81-249032

E-mail: mconci@ufpa.br

Presented at the Symposium on Sensory and Neuropsychological Losses Due to Mercury Intoxication and to Other Neurodegenerative Processes. Studies in Humans and in Animal Models. Águas de Lindóia, SP, Brazil, August 24, 2004.

Research supported by CAPESRENOR, CNPq-PNOPG, and FINEPPNOPG. L.C.L. Silveira and M.E. Crespo-López are recipients of $\mathrm{CNPq}$ and DCR-SECTAM/CNPq research fellowships, respectively.

Received April 28, 2005 Accepted November 1, 2005 $\ldots \ldots \ldots \ldots \ldots \ldots . . . \ldots$. . . . .

\section{Abstract}

Four populations in the Amazon area were selected for a comparative study of mercury-exposed and non-exposed populations: São Luiz do Tapajós, Barreiras, Panacauera, and Pindobal Grande. The highest mercury levels in human hair samples were found in São Luiz do Tapajós and Barreiras, greatly exceeding the limits established by the World Health Organization. Panacauera showed an intermediate level below $9 \mu \mathrm{g} / \mathrm{g}$. This was the first comparative and simultaneous evaluation of mercury exposure in the Amazon area. Also, thanks to this type of monitoring, we were able to eliminate the uncertainties about the reference dose. On the basis of these data, we can conclude that the mercury levels detected in exposed populations of the Tapajós River basin may be dangerous not only because they are above the World Health Organization limits, but also because the simultaneous mercury detection in non-exposed populations with similar characteristics provided a valid control and revealed lower mercury levels. Our results support the importance of continuous monitoring in both exposed and non-exposed populations.

Mercury is a metal extensively used in numerous applications due to its property of conducting electricity in liquid form. Nevertheless, mercury is also a volatile metal and its vapor is extremely toxic. Because of its unusual capacity to form amalgams or to combine with other metals, mercury has been used for more than 4500 years in mining activities for the recovery of precious metals. At present, Brazil is the first country in South America and the second in the world in gold production ( $80 \%$ from informal min- ing or "garimpagem"). Approximately 2000 to 3000 tons of mercury have already been released into the Amazon environment (1). Final recovery of gold particles is carried out by boiling the amalgam, which increases mercury emissions into the atmosphere. Also, deforestation and river damming contribute as the largest sources of mercury mobilization in the Amazon. This provokes the natural occurrence of mercury in soil and water, with the metal being available for methylation by aquatic organisms (2). Thus, methyl- 
mercury is biomagnified through the food chain, with fish consumption being the most significant source of dietary exposure for most riverside communities. In the fresh waters of the Amazon region, many fish species have already been monitored for mercury content, with increased levels having been detected, especially in piscivorous species (3). These studies have documented a considerable impact of environmental concentrations of mercury, and a frequent incidence of exposure levels with adverse effects on human health (3-5). In the Tapajós River basin, the main tributary of the Amazon River, epidemiological and toxicological data have shown riverside populations with a mercury content of more than $10 \mu \mathrm{g} / \mathrm{g}$ (limit of tolerance determined by the World Health Organization, WHO) in human hair samples (6). In addition, previous studies have already identified three cases of mild forms of chronic Minamata disease among 50 individuals with a mercury content of more than $20 \mu \mathrm{g} / \mathrm{g}(4,7)$.

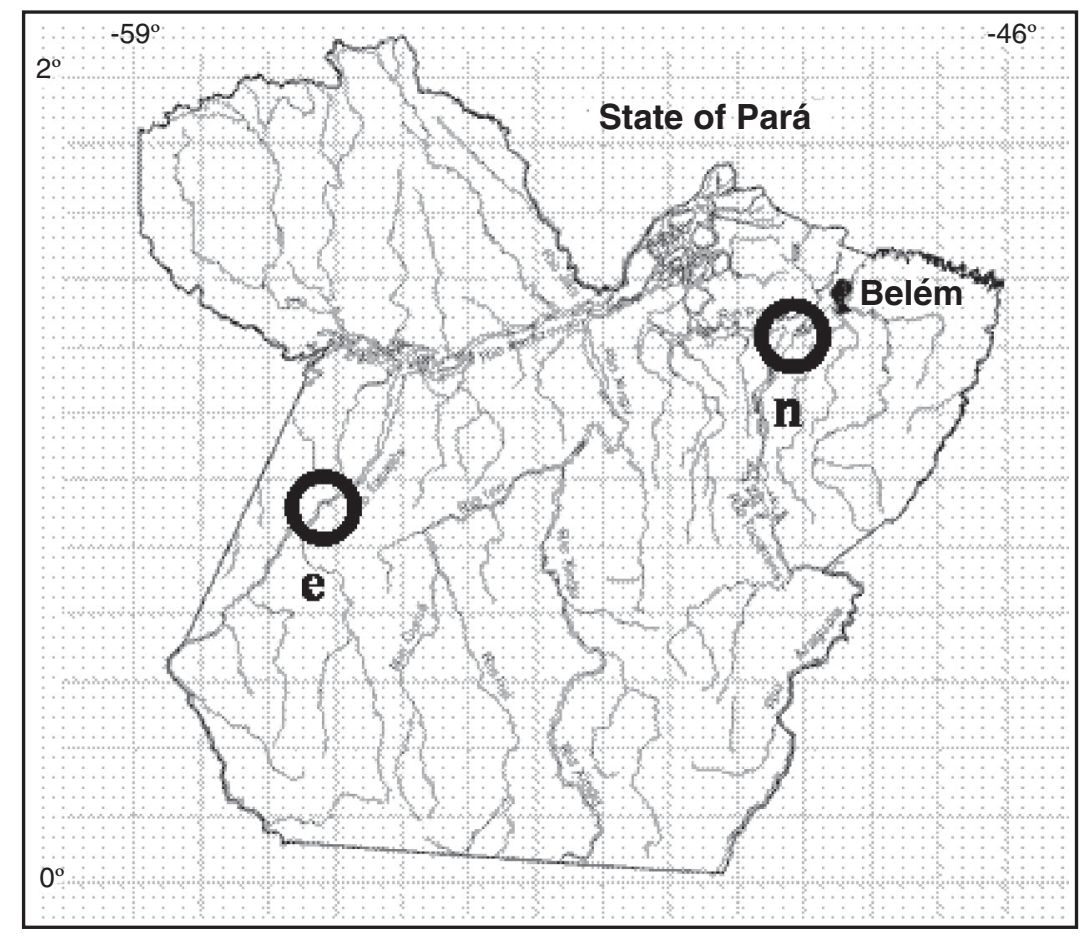

Figure 1. Location of exposed (e) and non-exposed (n) populations in this study.
Despite the tolerance values published in 1980 by the WHO, an increased polemic about the safety limits of mercury exposure has been generated in the last years (8). This controversy is based on the fact that longterm intake of relatively low levels of mercury initiates subclinical neurobehavioral abnormalities, especially regarding psychomotor coordination $(8,9)$. Thus, it is essential to take into account other factors such as individual susceptibility, life style or influence of occupational exposure for an adequate human monitoring.

Considering these factors, four populations in the Amazon area were selected to carry out a comparative study between mercury-exposed and non-exposed populations: two communities located along the Tapajós River (São Luiz do Tapajós and Barreiras) and two along the Tocantins River (Pindobal Grande and Panacauera). The first two communities are located in the southwest region of Pará State (Figure 1, e zone): São Luiz do Tapajós, situated $120 \mathrm{~km}$ upstream from Itaituba with approximately 460 inhabitants, and Barreiras, $80 \mathrm{~km}$ downstream from Itaituba with 740 inhabitants. Pindobal Grande and Panacauera are located in the northeast region of Pará State (Figure 1, n zone), $360 \mathrm{~km}$ downstream and $160 \mathrm{~km}$ upstream from Igarapé-Miri, respectively. Pindobal Grande has about 360 inhabitants and Panacauera about 260.

All populations are riverside communities with a very similar life style: among other similar characteristics, fishing and local agriculture represent the major activities and the diet includes a large number of fish meals per week. These populations differ in the influence exerted by regions with increased gold mining activities, very intense for the communities along the Tapajós River (São Luiz do Tapajós and Barreiras).

To analyze mercury exposure, hair samples (about $20 \mathrm{mg}$ ) from inhabitants selected according to inclusion and exclusion criteria, were collected with a scissor, cut- 
ting $1 \mathrm{~cm}$ above the insertion, from three different areas of the scalp. These samples were stored in paper envelopes, identified, sealed and transported to the laboratory for mercury analysis.

This study was performed according to the ethical parameters for human research defined by Resolution 164/86 of the National Health Council, Ministry of Health (Brazil), and approved by the National Council of Ethics in Research (CONEP, Brazil). All subjects tested gave informed consent to participate in the study.

Total mercury content was estimated in all hair samples using previously described techniques (10). Briefly, hair samples were cutted, washed with acetone, and heated in oven at $800^{\circ} \mathrm{C}$. Mercury vapor was collected in gold plates and analyzed by atomic absorption espectrophotometry. São Luiz do Tapajós, Barreiras, and Panacauera samples were analyzed at SEMAN (Seção de Meio Ambiente), Evandro Chagas Institute (Belém, PA, Brazil). Some of them were submitted to a second analysis at the Isotopic Characterization Group, Nuclear and Energetic Research Institute, São Paulo University (São Paulo, SP, Brazil), with more than $90 \%$ agreement among the different analytical procedures. Pindobal Grande samples were analyzed in the Laboratory of Ecotoxicology, Tropical Medicine Institute, Federal University of Pará (Belém, PA, Brazil), using a Mercury Analyzer SP 3D (Nippon Corporation, Tokyo, Japan). The precision and accuracy of these measurements were verified using the IAEA 085 International Reference Standard ( $>95 \%)$.

Two-way analysis of variance (ANOVA), followed by the Tukey post hoc test when appropriate, was used to compare means between groups, with the level of significance set at $\mathrm{P}<0.05$.

The study included a total of $32,37,22$, and 43 adults, ranging in age from 15 to 65 years, from São Luiz do Tapajós, Barreiras, Panacauera, and Pindobal Grande, respec- tively. Figure 2 summarizes the results obtained for these populations.

A comparative study with children also has been initiated since they constitute a group especially sensitive to DNA damage provoked by mercury that may trigger cancerigenous processes due to the accelerated development of children. Preliminary results for Pindobal Grande (88 children) have been included in Figure 2.

In adults, no significant difference $(\mathrm{P}>$ $0.05)$ in mercury content was found when different age ranges were compared for the same population, i.e., 15-24, 25-34, 25-44, $45-54$, and $>54$ years. Also, there was no difference between adults and children in mercury exposure for the Pindobal Grande population. The highest mercury levels were detected in the exposed populations of São Luiz do Tapajós and Barreiras, greatly exceeding the limit of $10 \mu \mathrm{g} / \mathrm{g}$. In non-exposed communities, the Panacauera population showed higher levels of mercury but still under $10 \mu \mathrm{g} / \mathrm{g}$. A similar value was previously found in the riverside community of Tabatinga, Pará State (11). These investigators also estimated the total mercury levels in other non-exposed communities of the Amazon region (Santana do Ituqui, Aldeia

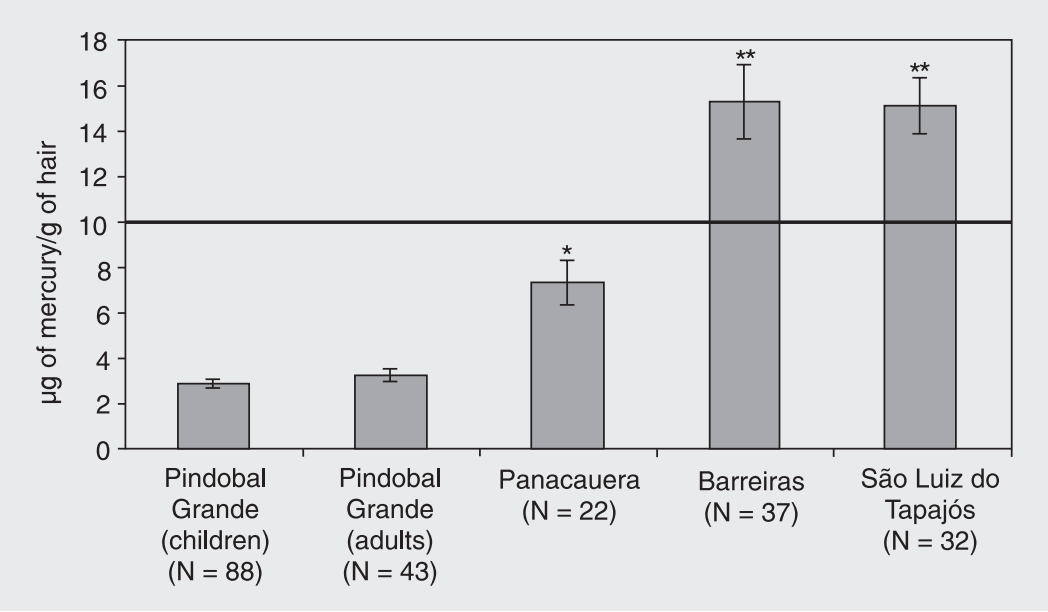

Figure 2. Total mercury content in hair samples from 2 regions of the Amazon. Data are reported as mean \pm SEM. The horizontal line at $10 \mu \mathrm{g} / \mathrm{g}$ indicates the limit determined by the World Health Organization. ${ }^{*} \mathrm{P}<0.001$ vs Panacauera and Pindobal Grande (adults and children); ${ }^{*} P<0.05$ vs Pindobal Grande (adults and children; Tukey post hoc test). 
do Lago Grande, and Caxiuanã, all of them located in Pará State) in an attempt to establish reference values for this area. Care is necessary with the use of these data because they are relatively old (some of them were obtained about 9 years ago) and the characteristics of the population may have changed.

The only way to obtain accurate evaluations is to conduct comparative and simultaneous studies in exposed and non-exposed populations. With the present investigation, this type of study in humans was carried out for the first time in the Amazon area.

In the present study, we were also able to eliminate the uncertainties about the reference dose thanks to the establishment of this type of monitoring in populations with similar characteristics. Now, with these data, we can already affirm that mercury levels detected in exposed populations of the Tapajós River basin may be dangerous not only because they are above the WHO limit, but also because the simultaneous mercury de- tection in non-exposed populations with similar characteristics worked as a valid control and revealed lower mercury levels. The present study supports the importance of continuous monitoring of both exposed and nonexposed populations. Knowledge originated by this monitoring will better assist the development of preventive strategies and government actions against the problem of mercury contamination.

\section{Acknowledgments}

We thank Dr. J. Sarkis (Grupo de Caracterização Isotópica, Instituto de Pesquisas Energéticas e Nucleares, Universidade de São Paulo) and E.C.O. Santos and E.S. Brabo (Seção de Meio Ambiente (SEMAM), Instituto Evandro Chagas, Belém) for carrying out the mercury analysis. Also, we would like to thank M.A. Gadelha and F.B. Xavier for their collaboration.

\section{References}

1. Lacerda LD (2003). Updating global mercury emissions from smallscale gold mining and assessing its environmental impacts. Environmental Geology, 43: 308-314.

2. Gochfeld M (2003). Cases of mercury exposure, bioavailability, and absorption. Ecotoxicology and Environmental Safety, 56: 174-178.

3. Dorea JG (2003). Fish are central in the diet of Amazonian riparians: should we worry about their mercury concentrations? Environmental Research, 82: 232-244.

4. Harada M (1997). Neurotoxicity of methylmercury: Minamata and the Amazon. In: Yasui M, Strong MJ, Ota K et al. (Editors), Mineral and Metal Neurotoxicology. CRC Press, New York, 177-188.

5. Lodenius M \& Malm O (1998). Mercury in the Amazon. Reviews on Environmental Contamination and Toxicology, 157: 25-52.

6. WHO (1980). Environmental Health Criteria 91. Methylmercury. World Health Organization, International Program on Chemical
Safety (IPCS), Geneva, Switzerland.

7. Harada M, Nakanishi J, Yasoda E et al. (2001). Mercury pollution in the Tapajos River basin, Amazon: mercury level of head hair and health effects. Environment International, 27: 285-280.

8. Dourson ML, Wullenweber AE \& Poirier KA (2001). Uncertainties in the reference dose for methylmercury. Neurotoxicology, 22: 677688.

9. Carta P, Flore C, Alinovi R et al. (2003). Sub-clinical neurobehavioral abnormalities associated with low level of mercury exposure through fish consumption. Neurotoxicology, 24: 617-623.

10. Akagi $\mathrm{H}$, Malm O, Kinjo $\mathrm{Y}$ et al. (1995). Methylmercury pollution in the Amazon, Brazil. Science of the Total Environment, 175: 85-95.

11. Santos ECO, Câmara VM, Jesus IM et al. (2002). A contribution to the establishment of reference values for total mercury levels in hair and fish in Amazonia. Environmental Research, 80: 6-10. 